\title{
Review: celecoxib is as effective as other NSAIDs and leads to fewer gastrointestinal adverse effects
}

\author{
Deeks JJ, Smith LA, Bradley MD. Efficacy, tolerability, and upper gastrointestinal safety of celecoxib for treatment of \\ osteoarthritis and rheumatoid arthritis: systematic review of randomised controlled trials. BMJ 2002;325:619-23. \\ QUESTION: In patients with osteoarthritis (OA) or rheumatoid arthritis (RA), is \\ celecoxib as effective as other non-steroidal anti-inflammatory drugs (NSAIDs)? Does \\ celecoxib have greater gastrointestinal (GI) safety than NSAIDs?
}

\section{Data sources}

Studies were identified by searching 3 electronic databases and by obtaining manufacturers' reports of industry sponsored randomised controlled trials (RCTs).

\section{Study selection}

Studies were selected if they were double blind RCTs that compared celecoxib at a licensed therapeutic dose for $\geq 12$ weeks with placebo or another NSAID in patients with active RA or OA.

\section{Data extraction}

1 reviewer extracted data from the original company trial reports. Multiple celecoxib treatment arms were combined for trials that randomised to $\geq 1$ dose.

\section{Main results}

9 RCTS (15 187 patients) were included. 5 RCTs included a placebo group. Follow up ranged from 12-52

\section{COMMENTARY}

Deeks $e t$ al did a systematic review and meta-analysis of all published trials comparing celecoxib (celebrex), a cyclooxygenase (COX) 2 inhibitor, with conventional NSAIDs or placebo for $\geq 12$ weeks. It was prepared for submission to the UK National Institute of Clinical Excellence (NICE) for appraisal of COX-2 selective inhibitors, and work of this quality should have a wider audience than the NICE panel alone. The results are generalisable to the type of $\mathrm{OA}$ and RA patient who agrees to participate in clinical trials. The authors present the efficacy data separately for OA and RA, but combine the safety data, arguing that "there is no evidence for a causal link between the nature of the disease, [ie, type of arthritis] and adverse events related to treatment". This is debatable because patients with RA are more likely to have the known risk factors for GI complications of NSAID therapy. ${ }^{1}$

The review concludes that celecoxib has equivalent efficacy to conventional NSAIDs in RA and OA. It is, however, substantially more expensive than conventional NSAIDs or even NSAIDs prescribed with proton pump inhibitors (PPIs). The reasons for prescribing celecoxib, therefore, rest with its GI safety profile. The incidence of ulcers detected on endoscopy was $71 \%$ lower in patients prescribed celecoxib than in those prescribed conventional NSAIDs. However, the incidence of ulcers was only reduced by $51 \%$ if patients required the co-prescription of low dose aspirin. Celecoxib is not free of GI side effects. $86 \%$ more patients allocated to celecoxib withdrew because of abdominal pain, and $60 \%$ more withdrew because of dyspepsia than those allocated to placebo.

In summary, celecoxib does have greater GI safety than conventional NSAIDs. The important, unanswered question is whether it has greater GI safety than an NSAID plus a PPI.

Deborah Symmons, MD, FRCP University of Manchester Medical School Manchester, UK

1 Fries JF, Miller SR, Spitz PW, et al. Gastroenterology 1989;96(2 Pt 2 Suppl):647-55.

weeks. $R A$ : celecoxib was better than placebo (2 RCTs) but not different from NSAIDs (3 RCTs) for improvement on the American College of Rheumatology 20\% improvement index and improvement in the number of tender or painful joints (table). $O A$ : celecoxib led to greater improvement than placebo on the Western Ontario and McMaster universities OA index for pain (3 RCTs) and joint stiffness (3 RCTs); celecoxib and NSAIDs did not differ for these outcomes (3 RCTs) (table). Tolerability: celecoxib led to more withdrawals because of adverse effects than placebo (5 RCTs), but rates were similar between celecoxib and NSAIDs (8 RCTs) (table). Celecoxib led to fewer withdrawals because of GI events than NSAIDs (8 RCTs) (table).

\section{Conclusion}

In patients with osteoarthritis or rheumatoid arthritis, celecoxib is as effective as non-steroidal antiinflammatory drugs and leads to fewer gastrointestinal adverse effects.

Sources of funding: Pfizer and Searle.

For correspondence: Dr JJ Deeks, Institute of

Health Sciences,

Headington, Oxford,

UK.

jon.deeks@cancer.org.uk

Celecoxib (Cele) v placebo or NSAIDs for rheumatoid arthritis (RA) or osteoarthritis $(O A) *$

\begin{tabular}{|c|c|c|c|c|c|}
\hline $\begin{array}{l}\text { Outcomes at } \\
12-52 \text { weeks }\end{array}$ & $\begin{array}{l}\text { Patient } \\
\text { group }\end{array}$ & Comparisons & $\begin{array}{l}\text { Weighted } \\
\text { event rates }\end{array}$ & $\mathrm{RBI}(95 \% \mathrm{Cl})$ & NNT (Cl) \\
\hline \multirow{2}{*}{$\begin{array}{l}\text { Met ACR-20 } \\
\text { responder } \\
\text { criteria }\end{array}$} & RA & Cele $v$ placebo & $38 \%$ v $26 \%$ & $49 \%$ (25 to 78$)$ & $9(6$ to 14$)$ \\
\hline & & Cele $v$ NSAIDs & $29 \%$ v $28 \% \dagger$ & $4 \%(-20$ to 36$) \dagger$ & Not significant \\
\hline \multirow{2}{*}{$\begin{array}{l}\text { Improvement in } \\
\text { numberof } \\
\text { painful/tender } \\
\text { joints }\end{array}$} & & Cele $v$ placebo & $48 \% \vee 34 \%$ & $39 \%$ (21 to 61$)$ & 8 (6 to 13$)$ \\
\hline & & Cele $v$ NSAIDs & $44 \% \vee 40 \% \dagger$ & $9 \%(-10$ to 32$) \dagger$ & Not significant \\
\hline & & & & $\mathrm{RRI}(\mathrm{Cl})$ & NNH (Cl) \\
\hline $\begin{array}{l}\text { Withdrawal } \\
\text { because of } \\
\text { any adverse } \\
\text { effect }\end{array}$ & All & Cele $v$ placebo & $8.8 \% \vee 6.2 \% \dagger$ & $48 \%(15$ to 92$) \dagger$ & $39(24$ to 117$) \dagger$ \\
\hline \multirow[t]{2}{*}{$\begin{array}{l}\text { Withdrawal } \\
\text { because of GI } \\
\text { adverse effect }\end{array}$} & & Cele $v$ placebo & $3.3 \%$ v $2.0 \%$ & $68 \%$ (7 to 165 ) & 80 (44 to 450$)$ \\
\hline & & & & RRR (Cl) & NNT (Cl) \\
\hline $\begin{array}{l}\text { Withdrawal } \\
\text { because of } \\
\text { any adverse } \\
\text { effect }\end{array}$ & & Cele $v$ NSAIDs & $8.5 \% \vee 9.7 \%$ & $14 \%(-4$ to 28$)$ & Not significant \\
\hline \multirow[t]{2}{*}{$\begin{array}{l}\text { Withdrawal } \\
\text { because of GI } \\
\text { adverse effect }\end{array}$} & & Cele $v$ NSAIDs & $3.6 \% \vee 6.3 \% \dagger$ & $46 \%$ (29 to 58 ) & $37(26$ to 67$) \dagger$ \\
\hline & & & \multicolumn{2}{|c|}{ Mean difference $(\mathrm{CI})$} & \\
\hline \multirow{2}{*}{$\begin{array}{l}\text { WOMAC pain } \\
\text { score }(0-20)\end{array}$} & $\mathrm{OA}$ & Cele $v$ placebo & \multicolumn{2}{|c|}{$-1.35(-1.74$ to -0.97$) \ddagger$} & \\
\hline & & Cele $v$ NSAIDs & \multicolumn{2}{|c|}{$-0.01(-0.73$ to 0.72$) \dagger$} & \\
\hline \multirow{2}{*}{$\begin{array}{l}\text { WOMAC joint } \\
\text { stiffnessScore } \\
(0-8)\end{array}$} & & Cele $v$ placebo & \multicolumn{2}{|c|}{$-0.65(-0.80$ to -0.49$) \ddagger$} & \\
\hline & & Cele $v$ NSAIDs & \multicolumn{2}{|c|}{$0.06(-0.11$ to 0.22$)$} & \\
\hline
\end{tabular}

